\section{Metal sulphides}

Mineral Chemistry of Metal Sulfides. By D. J. Vaughan and J. R. Craig. Pp. 493. (Cambridge University Press: Cambridge and London, 1978.) £19.50.

Metal sulphides are not only of concern to geologists in economic, petrological and sedimentological fields but also to metallurgists in many specialisms from the extractive industries to electronics. This book aims to lead all such workers through a variety of experimental and theoretical approaches into a clearer understanding of the range of natural and synthetic sulphides. The authors have made individual contributions to sulphide research and now they have assimilated a vast literature to produce a concise and balanced book.

The text and appendices contain an immense amount of well indexed data with generous references to original work; this will therefore be a satisfying handbook to investigators, but not a manual of experimental techniques. Vaughan and Craig, however, seem to have had the additional objective of teaching the willing reader who might be ignorant of one or other of the particular subjects covered, from crystal chemistry to determinative methods. In the introduction and elsewhere the underlying theory is introduced straightforwardly and without condescension.

Only four years after P. H. Ribbe's Short Course Notes on sulphide mineralogy (Mineralogical Society of America, 1974) it may be asked "why another publication on the same ground?". Although the aims and constraints are here somewhat different, one answer might be that Ribbe showed it could be done. Until that date the variety and complexity of the sulphides defied condensation; their classification was never as straightforward as that of the silicates, and only with the recent deployment of crystal chemistry to the explanation of sulphide structures has a more satisfying rationalisation been glimpsed. Sulphosalts will perhaps be the last to emerge from the jungle but anyone concerned with these not necessarily rarer variants will still have to rely on the reviews of Ribbe's contributors, as Vaughan and Craig dismiss them entirely in order to limit the size of their text.

Naturally this volume is altogether more polished. On the whole, it parallels the 1974 book on sulphide crystal chemistry and classification, with some later work to 1977 included, and also on chemical bonding, principal phase equilibria of sulphides and associated experimental methods, and current trends and prospects in the investigation of natural sulphides in geology.

Part of the distinctive trend of the book is found in the balancing chapters on electrical and magnetic properties and their applications, spectroscopic studies, classical (that is, including microscopic) determinative methods and sulphide thermochemistry. The chapter on sulphide equilibria in aqueous solutions leads to consideration of conditions in natural hydrothermal fluids and to the thermodynamics of sulphide solubility and deposition.

The final chapter discusses natural sulphides and recognises their differences from the pure and synthetic in their major, minor and trace element contents, solid solution phenomena and S-isotopic variation, the study and significance of all of which are introduced. Appendices contain mineralogical data on 319 sulphides, univariant sulphidation data and invariant points in sulphide mineral systems.

L. G. Love

L. G. Love is Senior Lecturer in Geology at the University of Sheffield, UK.

\section{SCIENTIFIC - BOOKS}

H. K. LEWIS can supply works in all branches of Pure and Applied Science. Catalogues on request. Please state interests.

\section{SCIENTIFIC LENDING LIBRARY}

Annual Subscription from $\$ 7.00$. (Available in U.K. only)

Reduced rates for multiple subscriptions.

Prospectus post free on request.

Quarterly List of New Books and new editions added to the Library sent post free to subscribers regularly.

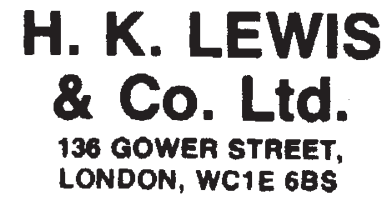

Twlephone: 01-397 4282 Telecrams: "Publicevilt, London, WC1E 6Bs."

Circle No. 23 on Reader Enquiry Card.

\section{Heterogeneous catalysis}

Dynamic Heterogeneous Catalysis. By K. Tamaru. Pp. 140. (Academic: London and New York, 1978) $£ 8.50$.

IT is difficult to know for whom this volume is intended. Its objective is to emphasise that an understanding of heterogeneous catalysis cannot be achieved by studies of the equilibrium states of solid/gas systems, but must be based on a study not only of the kinetics of catalysed reactions but also of the changes in adsorption on, and chemical properties of, the catalytic sites under working conditions. This thesis is widely accepted and has indeed been the objective of much research, particularly by the author and his coworkers. The complementary view, that one must first understand the nature of clean surfaces and their interaction with simple gases, is, however, implied by a great deal of recent work using modern techniques of surface physics, so that an attempt to strike a balance between the two would be timely.

One therefore expects this to be a research monograph. Instead, one finds a very uneven text including a great deal of elementary physical chemistry (for example, kinetic derivation of the
Langmuir isotherm, Langmuir-Hinshelwood kinetics, and a discussion of homogeneous gas reactions) with which the average research worker in the field will be very familiar. Yet the presentation is not sufficiently balanced to serve as a supplementary undergraduate text. The descriptions of various surface physics techniques-FEM, FIM, LEED, ELS, AES and PES-are very sketchy and hardly seem justified as only scant reference is made to them later in the book: again the research worker in this field will already be very familiar with these techniques.

The book consists of four chapters on: general reaction kinetics; adsorption; the kinetics of heterogeneous reactions; and the applications of spectroscopic techniques to the dynamic treatment of adsorbed species in reaction conditions. Only in the last chapter, in which the examples are drawn largely from the author's own work, does the main theme of the book begin to dominate.

Libraries carrying a comprehensive collection on catalysis will no doubt wish to have this book, but it is unlikely to attract a wide readership.

\section{H. Everett}

D. H. Everett is Leverhulme Professor of Physical Chemistry at the University of Bristol, UK. 